register as complete and accurate as possible. All information supplied will be treated as strictly confidential.

It is only by the aid of an up-to-date register that schemes for the welfare of the blind, now in operation or to be initiated, can be made to include all those entitled to benefit thereby.

\title{
Glaucoma produced by Homatropin
}

In the American Journal of Ophthalmology for September, 1917, there is a reference to a case of acute inflammatory glaucoma produced by one drop of one per cent. homatropin, recorded by Levitt, of Brooklyn. Why the Editor of the Journal has refrained from stating in what periodical Levitt reports his case, if indeed it has appeared in print at all, it is difficult to understand. But so it is ; no reference is given. In Levitt's case it appears that one drop of one per cent. homatropin employed for a fundus examination caused an attack of acute inflammatory glaucoma; but the age of the patient is not stated. All that is stated is that the eye which developed the glaucoma had tension minus one and was myopic.

\section{ABSTRACTS}

\section{I.-GLAUCOMA}

(I) McCaw, J. A.-The colloidal theory of the pathology of glaucoma. Ophthal. Record, June, I9I 5.

(1) McCaw has made some experiments to test the colloidal theory of glaucoma as advanced by Martin Fischer. His observations on the swelling of fibrin and sheep's eyes when placed in acid solutions, lead him to formulate the following conclusions :

An abnormal production or accumulation of acids, or conditions predisposing thereto, exist in all states in which we encounter the development of oedema. Pathologically considered, glaucoma is a local oedema, and, clinically considered, all the symptoms of this disease are referable to the increase of intra-ocular pressure induced by the large amount of water held by the eye. An intense glaucoma can be induced without any circulation whatever, whilst you may have an increase of pressure in the circulating fluids of the eye without any symptom of glaucoma. "This leads us to the conclusion that the cause of glaucoma may well reside in the tissues of the eye, and that it becomes glaucomatous, not because there is more fluid pressed into it, but because through changes in it, it absorbs more 